\title{
Therapeutic hypothermia in asphyxiated newborns: selective head cooling vs. whole body cooling - comparison of short term outcomes
}

\author{
Ewa Matylda Gulczynska ${ }^{1}$, Janusz Gadzinowski ${ }^{2}$, Marcin Kesiak', \\ Barbara Sobolewska ${ }^{1}$, Joanna Caputa ${ }^{2}$, Anna Maczko ${ }^{3}$, Wojciech Walas ${ }^{3}$, \\ Wioletta Cedrowska-Adamus ${ }^{1}$, Tomasz Talar ${ }^{3}$ \\ ${ }^{1}$ Department of Neonatology, Polish Mother Memorial Hospital - Research Institute, Lodz, Poland \\ ${ }^{2}$ Department of Neonatology, Poznan University of Medical Sciences, Poznan, Polska \\ ${ }^{3}$ Pediatric Intensive Care Unit, University Hospital in Opole, Poland
}

\begin{abstract}
Objectives: Therapeutic hypothermia TH became broadly used in the management of the asphyxiated newborns. Although two cooling methods are used, so far the superiority of none of them has been established. The purpose of the study is to compare two cooling methods: selective head cooling (SHC) and whole body cooling (WBC)

Material and methods: We conducted a prospective observational study in newborns with HIE. The patients received one of methods: SHC or WBC. The eligibility criteria were similar to previous studies. Stability of cardio-respiratory parameters and short term outcomes were analyzed.

Results: 78 neonates with hypoxic-ischemic encephalopathy due to perinatal asphyxia were involved in this study. The SHC group consisted of 51 newborns, the WBC group consisted of 27 patients. Both study groups had similar baseline characteristics and condition at birth. There were no significant differences in hospital course, neurological status and adverse effects associated with cooling procedure between groups. Analyzing the rate of thrombocytopenia and the number of transfusions of blood components no statistically significant differences were found between the groups.

Conclusions: Results of our study indicate that two compared methods of TH despite varied target core temperature ranges do not differ significantly according to clinical course and risk of adverse events. Further observations are conducted and we look forward to the results of the long neurodevelopmental care.
\end{abstract}

Key words: asphyxia; hypoxic-ischemic encephalopathy; newborn; selective head cooling; whole-body cooling

Ginekologia Polska 2019; 90, 7: 403-410

\section{INTRODUCTION}

Despite the advances in perinatal care, asphyxia of neonates remains a serious condition leading to significant mortality and morbidity. According to WHO about 2.6 million of deaths occur annually in the neonatal period. Perinatal asphyxia represents the third most common cause of neonatal death (23\%) after preterm birth (28\%) and severe infections (26\%). It means that all over the world, almost 600000 newborns die every year and at least the same number develop severe consequences such as epilepsy, cerebral palsy and developmental delay due to acute perinatal sentinel events [1].

In the 90 s of the last century, it was confirmed that the decline in brain temperature by $2^{\circ} \mathrm{C}$ to $5^{\circ} \mathrm{C}$ provided neuroprotection [2-4]. Encouraging results of the first applications of therapeutic hypothermia in human neonates enabled to construct prospective randomized trials, initially with a control (not cooled) group of asphyxiated newborns. Research results, since the pioneering studies $[5,6]$ through the multicenter trials, were convincing and led to immediate acceptance of medical devices for TH by the FDA [7-12]. The outcomes of RCT studies confirmed the lower mortality rates and improvement of neurodevelopmental outcomes in cooled neonates. Current guidelines for neonatal resuscitation (since 2010) recommend the use of therapeutic hypothermia as a standard treatment in newborns with moderate or severe hypoxic-ischemic encephalopathy.

The Olympic Cool-Cap providing selective head cooling with mild systemic hypothermia was the first method of cooling approved by FDA in 2006 to be used in newborns with HIE. 
Subsequently, in 2010 Tecotherm Neo device — Inspiration was introduced into the European market and at the same time (2010 and 2014) Arctic Sun TMS and Blanketrol AE; received the acceptance of the FDA. Apart from the Cool-Cap all the other devices mentioned above were dedicated to the second method of hypothermia: whole body cooling (WBC). The indications for hypothermia include: an acute hypoxia incident, Apgar score $\leq 5$ in $10 \mathrm{~min}$, resuscitation for $10 \mathrm{~min}$ after birth or severe acidosis ( $\mathrm{pH}<7$ or BE $>16 \mathrm{mmol} / \mathrm{L}$ ) (in umbilical cord blood or in the first $60 \mathrm{~min}$ after birth), neurological symptoms of moderate or severe hypoxic-ischemic encephalopathy and pathological aEEG recording [13]. Because of a very short therapeutic window after perinatal sentinel events the treatment with $\mathrm{TH}$ should be started in the first 6 hours of life and continued for 72 hours. The inclusion criteria also contain: the maturity above 36 weeks of pregnancy and birth body weight $>1800 \mathrm{~g}$. Although whole body cooling is now more popular and more commonly exploited, both methods are used and considered as appropriate and equivalent [14]. So far we have only a few studies comparing the two aforementioned methods of therapeutic hypothermia of newborns [15]. The superiority of either, SBC or WBC, has not been established.

\section{MATERIAL AND METHODS}

The prospective observational study was carried out in three centers. Two NICUs at level III perinatal centers and one Pediatric Intensive Care Unit participated in this study. The inclusion criteria were consistent with earlier randomized control trials: post menstrual age $\geq 36$ weeks, Apgar $\leq 5$ at 10 minutes of life and umbilical cord blood $\mathrm{pH}<7.1$ and/or base excess $(\mathrm{BE}) \geq 16 \mathrm{mmol} / \mathrm{L}$, respiratory support until $10^{\text {th }}$ minute of life. The exclusion criteria involved: major congenital malformations, life-threatening abnormalities and extremely poor prognosis (i.e. Apgar score 0 for longer than 10 minutes of life). Subsequently, all the considered infants were neurologically examined according to Sarnat classification [16]. Newborns with clinical symptoms of moderate or severe HIE were further assessed with integrated EEG by means of infant electroencephalography Monitor Olympic CFM ${ }^{\mathrm{TM}} 6000$, Natus Medical, USA. Moderately or severely abnormal aEEG traces were the entry criteria for therapeutic hypothermia. The selection of the cooling method, either WBC or SHC, depended on the cooling equipment available at the time in the care unit. The study protocol received the ethics approval of the bioethical board - PMMH - Research Institute Ethical Committee. Informed consent was obtained from all the legally designated representatives of the study neonates.

\section{Therapeutic hypothermia protocol}

Therapeutic hypothermia was initiated in the first 6 hours of life and continued for 72 hours. The cooling pe- riod was followed by a rewarming phase and the rewarming speed was set at $0.5^{\circ} \mathrm{C}$ per hour. Throughout the course of the cooling and rewarming process, vital signs (heart rate, arterial blood pressure, rectal temperature) and parameters of respiratory support $\left(\mathrm{FiO}_{2}, \mathrm{MAP}\right.$, level of respiratory support) were monitored and recorded every hour for the first 6 hours, then every three hours, and again every hour during the rewarming. A total of 36 measurements were taken. The vital signs were monitored using Philips IntelliVue MP70 Neonatal Monitors or Drager Infinity ${ }^{\circledR}$ Delta Monitors.

The use of medicines like: vasopressors, anticonvulsants, steroids, volume expanders and inhaled nitric oxide were recorded. Parameters of coagulation were followed closely and the number of blood components transfusions (platelets, fresh frozen plasma, red blood cells) during the first 7 days of life were noted. Additionally, clinical data such as the number of seizure episodes, the incidence of IVH detected by cranial USG, the rate of PPHN confirmed by ECHO exam and feeding difficulties were analyzed. The assessment of the neurological status of the studied infants was carried out daily by trained personnel using the Thompson Encephalopathy Score [17] .

\section{Statistical analysis}

In order to compare the percent accuracy between groups Chi-square or Fisher exact test were applied. One-way or two-way analysis of variance (ANOVA) was used for continuous data to investigate the differences between groups and changes observed over time. Fishers LSD (least significant difference) post hoc comparison tests were used to identify any significant differences between mean values. Differences in the means of the ranks of the values between groups were analyzed with the Student's t-test or Mann-Whitney U test. Statistical analysis was carried out using STATISTICA (StatSoft, Tulsa, OK, USA, version 6.0 PL). Statistical significance was assumed at $p$-value $<0.05$.

\section{RESULTS}

Seventy nine neonates were included in this study. The SHC group consisted of 51 newborns, the WBC group was composed of 27 patients. Table 1 shows demographic and clinical data of the study population.

Groups had similar baseline characteristics and condition at birth. $\mathrm{pH}, \mathrm{BE}$ values in umbilical cord blood, rectal temperature at admission and neurological assessment on the initiation of the cooling procedure were also similar between the groups. The majority of the analysed patients: 21 out of 27 (77.8\%) of patients in WBC and 42 out of 51 (82.4\%) patients in the SHC were outborn so neonatal interfacility transport was used. Emergency C-section procedure rates did not differ between groups: $74.1 \%$ vs. $69.8 \%$. Therapeutic hypothermia initiation time equaled 
Table 1. Demographic data and clinical characteristics of the study subjects

\begin{tabular}{|c|c|c|c|}
\hline & $\begin{array}{l}\text { SHC } \\
51\end{array}$ & $\begin{array}{l}\text { WBC } \\
27\end{array}$ & p-value \\
\hline $\begin{array}{l}\text { Postmenstrual age [weeks]; } \\
\text { mean }( \pm \text { SD) }\end{array}$ & $38.53( \pm 1.7)$ & $38.96( \pm 1.9)$ & 0.71 \\
\hline Female gender, number (\%) & $23(43.4)$ & $19(70.3)$ & 0.33 \\
\hline $\begin{array}{l}\text { Birth body weight }[g] \\
\text { mean }( \pm S D)\end{array}$ & $3213.6(576.2)$ & $3276.9(625.7)$ & 0.31 \\
\hline Cesarean delivery (\%) & $37(69.8)$ & $20(74.1)$ & 0.69 \\
\hline $\begin{array}{l}\text { Apgar score: } \\
\text { @ } 5 \text { minutes; } \\
\text { @10 minutes, }\end{array}$ & $\begin{array}{l}2.84( \pm 1.71) \\
3.54( \pm 1.70)\end{array}$ & $\begin{array}{l}2.11( \pm 1.89) \\
2.92( \pm 1.87)\end{array}$ & $\begin{array}{l}0.08 \\
0.15\end{array}$ \\
\hline Umbilical blood $\mathrm{pH}^{\mathrm{a}}( \pm \mathrm{SD})$ & $6.89(0.151)$ & $6.87(0.184)$ & 0.62 \\
\hline Outborns n (\%) & $42(82.4)$ & $21(77.8)$ & 0.63 \\
\hline Base excess $(\mathrm{BE})^{*}$ & $-19.92( \pm 4.8)$ & $-19.78( \pm 4.8)$ & 0.92 \\
\hline $\begin{array}{l}\text { Rectal temperature } \\
\text { at admission }\left[{ }^{\circ} \mathrm{C}\right]\end{array}$ & $33.8( \pm 1.81)$ & $33.7( \pm 1.63)$ & 0.86 \\
\hline $\begin{array}{l}\text { HIES (Thompson scale) } \\
\text { at }<6 \text { hrs of age } \\
7^{\text {th }} \text { day of life }\end{array}$ & $\begin{array}{l}10.36 \\
1.87\end{array}$ & $\begin{array}{l}11.06 \\
2.66\end{array}$ & $\begin{array}{l}0.49 \\
0.75\end{array}$ \\
\hline Neonatal seizures prior to cooling $(n ; \%)$ & $26(51.0)$ & $7(26.9)$ & 0.04 \\
\hline $\begin{array}{l}\text { TH initiation time } \\
\text { [minutes of life] }\end{array}$ & $317( \pm 167)$ & $357.0( \pm 122)$ & 0.08 \\
\hline
\end{tabular}

The difference $p$-value of $<0.05$ was considered statistically significant

athe worst values: umbilical cord blood or any blood sampling during the first hour after birth

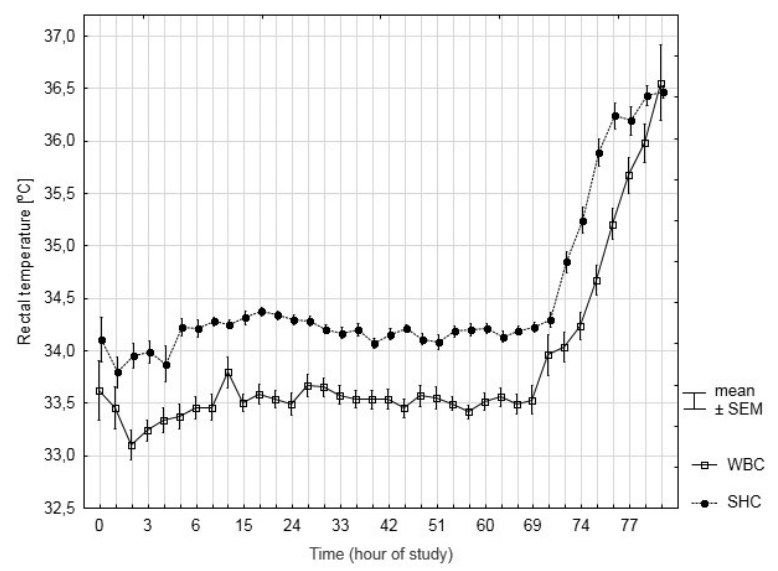

Figure 1. Time sequence of changes in rectal temperature. The average rectal temperature during the maintenance and re-warming phase (WBC vs. SHC)

(mean, \pm SD) $357( \pm 122)$ and $317( \pm 167)$ minutes in the WBC and $\mathrm{SHC}$ respectively ( $\mathrm{p}$-value 0.08 ).

The rectal temperature evidently varied between the groups: during the maintenance phase of hypothermia the average temperature in the WBC group was $33.5^{\circ} \mathrm{C}$ whereas in the SHC it amounted to $34.2^{\circ} \mathrm{C}$ ( $p$-value 0.000 ). During the rewarming phase the differences gradually decreased reaching normothermia (Fig. 1).

In the WBC group the mean HR values equaled $116.4(\mathrm{SD} \pm 21.1) \mathrm{bpm}$, whereas in the SHC group 114.9

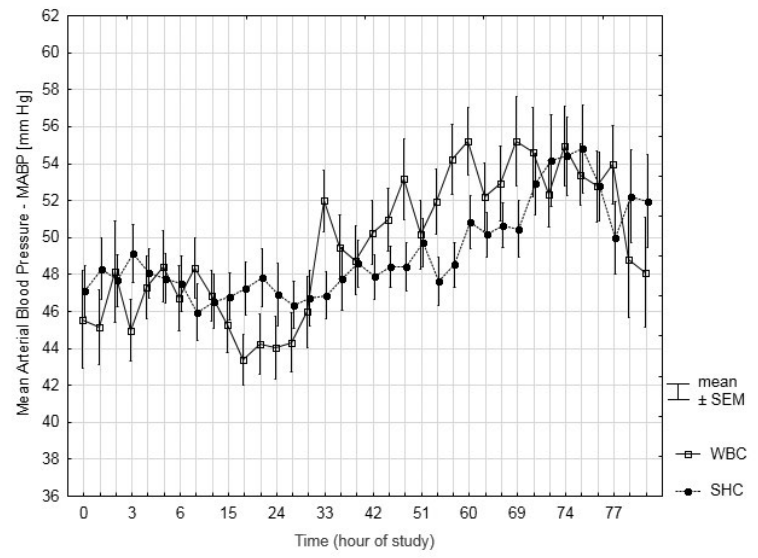

Figure 2. Mean arterial blood pressure during the whole TH procedure in the WBC and $\mathrm{SHC}$ groups $[\mathrm{mmHg}]$

( \pm 20.1) bpm; (p-value 0.58). A similar observation concerned measurements of the mean arterial blood pressure which amounted to (mean \pm SD) $51.1( \pm 10.2) \mathrm{mmHg}$ in the WBC group and to 49.4 ( \pm 9.9) in the SHC group, however, a tendency to lower MABP was found in the SHC, ( $p$-value 0.099). Nonetheless, the difference between the groups was not statistically significant. Mean arterial pressure (MAP) in the 36 points of measurement in WBC and SHC groups are shown in Figure 2. Time 0 in these and subsequent figures designates the initiation of the cooling procedure. 
Table 2. Hospital Course and Status at Discharge. Analysis of drug and blood components administration in the first week of life

\begin{tabular}{|c|c|c|c|}
\hline & $\begin{array}{l}\text { SHC } \\
51\end{array}$ & $\begin{array}{l}\text { WBC } \\
27\end{array}$ & p-value \\
\hline $\begin{array}{l}\text { Respiratory support No [\%] } \\
\text { mean [days] }( \pm \text { SD) }\end{array}$ & $4.8( \pm 3.6)$ & $6.0( \pm 6.6)$ & 0.37 \\
\hline $\begin{array}{l}\text { Noninvasive support [days] } \\
\text { mean }( \pm \text { SD })^{\text {aa }}\end{array}$ & $0.7( \pm 1.3)$ & $1.5( \pm 3.6)$ & 0.26 \\
\hline $\begin{array}{l}\text { Oxygen therapy [days] } \\
\text { mean }( \pm \text { SD) }\end{array}$ & $5.6( \pm 7.6)$ & $4.5( \pm 3.8)$ & 0.47 \\
\hline $\begin{array}{l}\text { Diagnosis of PPHN } \\
\text { Administration of inhaled NO (INO) }\end{array}$ & $\begin{array}{l}6(11.3) \\
2(3.8)\end{array}$ & $\begin{array}{l}5(18.5) \\
4(14.8)\end{array}$ & $\begin{array}{l}0.38 \\
0.08\end{array}$ \\
\hline $\begin{array}{l}\text { Thrombocytopenia } \\
100000 / \text { microliter ( } \mu \mathrm{L}) \\
\text { Number; }(\%)\end{array}$ & $\begin{array}{l}23 \\
45.1\end{array}$ & $\begin{array}{l}12 \\
45.1\end{array}$ & 0.93 \\
\hline $\begin{array}{l}\text { RBC transfusion } \\
\text { (No; No of patients) } \\
\text { No/patient }\end{array}$ & $\begin{array}{l}10 / 6 \\
0.2\end{array}$ & $\begin{array}{l}7 / 5 \\
0.28\end{array}$ & 0.46 \\
\hline $\begin{array}{l}\text { FFP transfusion } \\
\text { (No; No of patients) } \\
\text { No/all patients }\end{array}$ & $\begin{array}{l}20 / 12 \\
0.39\end{array}$ & $\begin{array}{l}24 / 13 \\
0.89\end{array}$ & 0.36 \\
\hline $\begin{array}{l}\text { PLT transfusion } \\
\text { No/patient }\end{array}$ & $\begin{array}{l}5 / 5 \\
0.1\end{array}$ & $\begin{array}{l}4 / 3 \\
0.16\end{array}$ & 0.30 \\
\hline $\begin{array}{l}\text { Catecholamine use: } \\
\text { none } \\
1 \\
\geq 2 \\
\text { Mean No of days/all patients }\end{array}$ & $\begin{array}{l}18(35.3 \%) \\
19(31.4 \%) \\
17(33.3 \%) \\
3.14\end{array}$ & $\begin{array}{l}12(44.4 \%) \\
1(3.7 \%) \\
14(51.8 \%) \\
4.04\end{array}$ & $\begin{array}{l}0.08 \\
0.19\end{array}$ \\
\hline $\begin{array}{l}\text { Volume replacement therapy } \\
\text { (No; No of patients) } \\
\text { No/patient }\end{array}$ & $\begin{array}{l}5 / 5 \\
0.2\end{array}$ & $\begin{array}{l}13 / 9 \\
0.25\end{array}$ & 0.20 \\
\hline $\begin{array}{l}\text { Anticonvulsant administration } \\
\text { (No of patients) } \\
\text { No of doses/all patients }\end{array}$ & $\begin{array}{l}40 \\
141 / 2.8\end{array}$ & $\begin{array}{l}24 \\
80 / 2.9\end{array}$ & 0.94 \\
\hline Antibiotic therapy [days] mean $( \pm S D)$ & $14.5( \pm 7.6)$ & $13.1( \pm 6.8)$ & 0.43 \\
\hline $\begin{array}{l}\text { Full enteral feeding } \\
\text { Oral feedings (sucking) } \\
\text { [days] mean ( } \pm \text { SD) }\end{array}$ & $\begin{array}{l}14.5( \pm 5.9) \\
16.7( \pm 10.2)\end{array}$ & $\begin{array}{l}14.7( \pm 5.1) \\
14.3( \pm 5.4)\end{array}$ & $\begin{array}{l}0.92 \\
0.37\end{array}$ \\
\hline Age at discharge/DOL mean $( \pm \mathrm{SD})$ & $27.26( \pm 13.0)$ & $21.91( \pm 11.3)$ & 0.09 \\
\hline Death during hospital stay n (\%) & $3(6.0)$ & $2(8.3)$ & 0.71 \\
\hline
\end{tabular}

The $p$-value of $<0.05$ was considered statistically significant

any type of mechanical ventilation (SIMV, PC, HFOV)

aa any type of noninvasive respiratory support (noninvasive ventilation, nasal CPAP)

The analysis of the frequency of inotropes use did not reveal significant changes. Additionally, the mean number of days of inotropes administration calculated on the number of people in the group was not statistically significant (Tab. 2) .

When analyzing the course of hospitalization and the rate of complications, no differences were found. The respiratory support and oxygen supplementation time were not significantly different. However, the rate of neonates who required any respiratory support (MV or noninvasive support) between $36-80$ hour of cooling was significantly higher in the WBC vs. SHC group, $83.6 \%$ vs. $72 \%$ respectively; ( $p$-value 0.047 ). During the whole therapeutic hypothermia procedure the fraction of inspired oxygen ( $p$-value 0.99) and mean airway pressure ( $p$-value 0.68 ) did not differ between the groups.

The rate of PPHN decreased and the need for inhaled nitric oxide (INO) was reduced three-fold in the SHC group but the rate of its incidence was very low. The average platelets count in all controlled tests was similar in both groups. In the WBC group a statistically significant decrease in mean PLTs values was observed on the $2^{\text {nd }}, 3^{\text {rd }}$ and $4^{\text {th }}$ days compared to baseline values in the first 24 hours. The reduction in the following days reached $38 \%$ of the initial value. A smaller reduction in average platelets values was observed in the SHC group, by only $21 \%$. The incidence of 


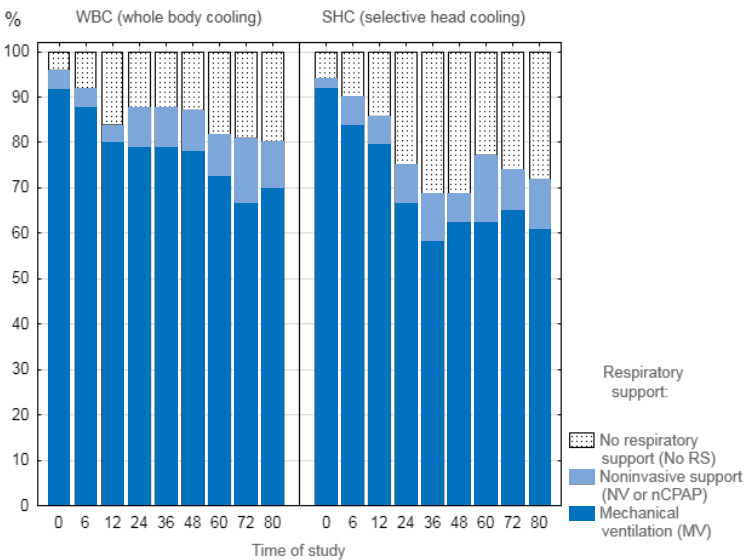

Figure 3. The mode of respiratory support in the WBC and SHC groups during the whole TH procedure. Any type of applied mechanical ventilation (SIMV, PC, HFOV) and noninvasive respiratory support (noninvasive ventilation, nasal CPAP) were analyzed jointly

thrombocytopenia $100 \times 10^{9} / \mathrm{L}$ found in each of the groups did not differ statistically significantly; ( $p$-value 0.93 ). Also, the number of transfusions of different blood components (fresh frozen plasma, erythrocytes and platelets) did not differ significantly (Tab. 2).

Results of neonatal neurological status assessment performed daily according to Thompson scale are presented in Figure 3. On the following days of the treatment, to the fifth day of study (after the hypothermia was completed), the score was comparable in both groups. The rate of neurological status improvement expressed as a percentage decrease in Thompson scores was slightly better in SHC i.e. by $83.1 \%$ vs. $74.3 \%$ in WBC group in comparison with initial values.

\section{DISCUSSION}

Currently, therapeutic hypothermia is a standard treatment of hypoxic-ischemic encephalopathy in neonates [18]. The SHC was the first method of therapeutic hypothermia utilized in the neonatal period. The only device is a system utilizing a special cooling cap to provide selective brain cooling while maintaining core temperature at safe levels through the use of a radiant warmer. The Cool-Cap works by maintaining a steady flow of cool water at a selected temperature through a plastic cap covering the infant's head. The temperature is manually controlled. In this way the newborn's brain is the coldest part of the body. The rectal temperature is maintained at the level of $34.0-35.0^{\circ} \mathrm{C}$.

When using the second method, whole body cooling (WHC), the temperature distribution is reversed. In such case, hypothermia is delivered in newborn infants using different types of mattresses or wraps around the body. The newborn's brain cools backward through transfer of low temperature from the rest of the body. The temperature of the neonatal brain is probably higher compared to the tem- perature in the rectum. Therefore, the target rectal temperature in the WBC method is slightly lower and maintained at the level of $33.5 \pm 0.5^{\circ} \mathrm{C}$. Nowadays, the whole body cooling method seems more popular and more often used. However, both methods are used as before and considered equivalent in terms of effectiveness. Because the target ranges of deep body temperature are different, many users pose a question of the side effects as well as the effectiveness of both methods. In the animal model (piglet), which has a much smaller head compared with the human newborn infant, using SHC it was possible to cool the basal ganglia to the temperature lower by $5^{\circ} \mathrm{C}$ than rectal temperature [18], however, in adults, a considerable temperature gradient between the surface of the head and deep brain structures, where the temperature is similar to rectal temperature (Trec), was observed. Therefore, deep brain temperature remains almost equal to core temperature even when extreme cold is applied to the surface of the head [19]. It seems possible that the temperature gradient between head surface and deep brain structure could be substantial and may have an influence on regional brain temperature. Theoretically, it is possible that fluctuations in Trec and, in consequence, brain temperature may adversely affect the neuroprotective effect of TH. There is evidence that brain temperature is an important factor in regulating BBB permeability, alterations in brain water homeostasis and subsequent structural abnormalities of brain cells [20]. So far, we have only a few studies comparing the two methods of therapeutic hypothermia employed in neonatal period [15].

As expected, in our studied group differences in Trec were observed. The mean Trec in WBC group was $33.5^{\circ} \mathrm{C}$ and was the same as noticed in TOBY trial [21]. In the SHC group mean Trec was only $34.2^{\circ} \mathrm{C}$, which means that the differences were smaller than expected and amounted only to $0.66^{\circ} \mathrm{C}$. It may express the tendency of the medical team to maintain a target temperature in the lower ranges in manually controlled devices. The stability of vital parameters: mean target Trec, ABP, and HR at hourly intervals were previously assessed by Hoque et al. [22]. They compared four groups of newborns: 1 group treated with $\mathrm{SHC}$, and 3 groups receiving different variants of $W B C$. The authors did not find differences in mean ABP or mean HR between groups during the maintenance phase of cooling. They noticed greater variation in Trec in the SHC group during rewarming phase. No other clinical outcomes were analyzed.

Earlier studies have shown the effect of hypothermia on the frequency of inotropic agents used [7]. Meta-analysis of previous RCT (TH vs. control group) assessed cardiovascular effect and revealed increased risk of hypotension treated with inotropes in hypothermia group RR $1.17(95 \% \mathrm{Cl}$ $1.00,1.38), \operatorname{RD} 0.08(0.00,0.17)$ [23]. In our research, despite the obvious depth temperature measurements (Trec) dif- 
ferences, we did not notice differences in the mean HR as well as mean $A B P$ between groups. The rate and duration of inotropes administration were also similar. This observation is consistent with reports by other experts [24]. Although the SHC group was cooled using the standardized Cool Cap device, the low-tech method (cooling the baby's environment using a room air conditioner) was used in the WBC group. No differences in the following clinical parameters: low blood pressure, bradycardia, thrombocytopenia, coagulopathy, renal failure, necessity of respiratory support and discontinuation of mechanical ventilation or PPHN were identified during the cooling and rewarming procedure. Likewise, a non-randomized trial conducted at University of Michigan (WBC-28, SHC-31) confirmed that important components of multi-organ system dysfunction and hypotension treated with inotropes for $>24 \mathrm{~h}$, commonly required in newborns with $\mathrm{HIE}$, were similar for both methods of TH $[25,26]$.

The requirement for invasive mechanical ventilation, ability to perform extubation during the period of cooling and risk of PPHN were analyzed in two studies [25, 27]. No differences were found between groups in regard to the need of mechanical ventilation during the cooling or ability to be extubated during the cooling. In both analyses the rate of mechanical support while the cooling was being carried out was above $90 \%$. In addition, the possibility of extubation and newborns breathing on their own during the cooling procedure was confirmed (WBC $42.8 \%$ vs. SHC $37.9 \%$ ). The highest values of peak inspiratory pressure (PIP), positive end-expiratory pressure (PEEP), $\mathrm{FiO}_{2}$ (fraction of inspired oxygen), and $\mathrm{PaCO}_{2}$ (partial pressure of carbon dioxide) were investigated during the cooling procedure. No differences were found in the above mentioned respiratory settings between WBC and SHC groups [28]. Our findings are consistent with previous studies. Initially mechanical support was required by $92 \%$ of neonates in both groups, but at 72 hours of cooling artificial ventilation was used only in $65.2 \%$ SHC vs. $66.6 \%$ WBC. As was the case in the literature quoted earlier, we did not observe significant differences between analyzed groups. (Fig. 4, Tab. 2). In all three studies, the PPHN risk was higher in the WBC group but it did not reach statistical significance.

Thrombocytopenia is one of the most frequently reported side-effects of therapeutic hypothermia and its incidence is significantly different and varies from 3-65\%. Differences are probably related to definitions of thrombocytopenia and differences in timing of platelet count assessment [28]. Meta-analysis of four trials [5,6, 19] showed statistically significantly increased thrombocytopaenia in the hypothermic groups (RR: $1.55,95 \% \mathrm{Cl}: 1.14,2.11, \mathrm{NNH}$ : $8,95 \% \mathrm{Cl}: 5,50)$ [29]. The next analysis (8 RCT) confirmed a risk of thrombocytopenia in the hypothermia group RR

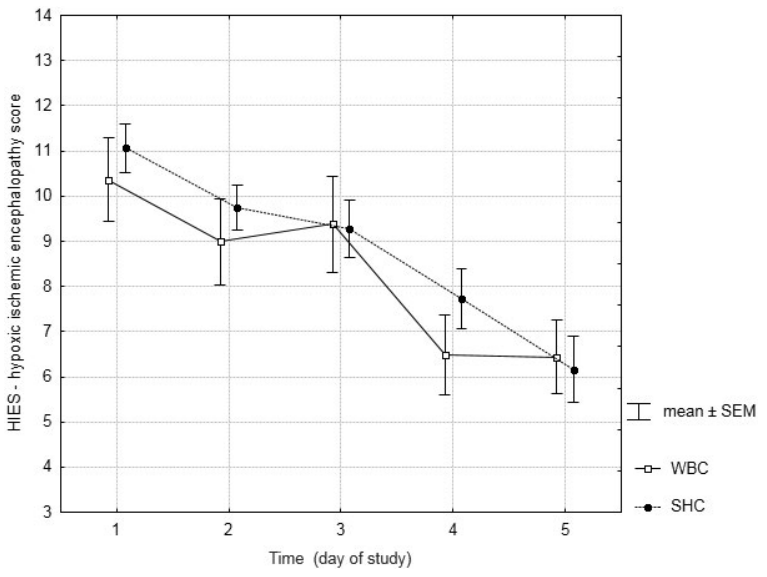

Figure 4. HIES - hypoxic ischemic encephalopathy score during the 5th first days of life

1.21 (95\% Cl 1.05-1.40) [23, 30]. The observed difference suggests an additional effect of hypothermia on platelet count in infants with perinatal asphyxia. A slight statistical increase in the risk of thrombocytopenia was detected in the group of infants treated with SHC [23]. In our study the frequency of thrombocytopenia was $32.7 \%$ (SHC) vs. $37 \%$ (WBC) and no statistical differences were observed. The aforementioned research conducted by Atici did not notice the differences in the risk of thrombocytopenia either [24]. Moreover, other researchers reported no differences in organ failure parameters including haematological, coagulogical and cardiovascular ones [31].

The same team of researchers conducted a small randomized study (17 in SHC vs. 12 in WBC group) and recorded the death rate at 41 vs. $33 \%$ and survivors without disability of 18 vs. 33\% in the SHC and WBC respectively [32]. However, the differences did not reach the level of statistical significance, which may be ascribed to a limited study group. Finally, the same authors analyzed certain neural and inflammatory biomarkers. The serum interleukin (IL)-1 $\beta$, IL-6, neuron-specific enolase (NSE), brain-specific creatine kinase (CK-BB), tumor necrosis factor-alpha (TNF-a), protein S100 levels, the urine S100B level and the urine lactate/creatinine $(\mathrm{L} / \mathrm{C})$ ratio were evaluated 6 and $72 \mathrm{hrs}$ after birth. They did not observe significant differences between groups at assessed time points, neither did they find such differences when the changes between 6 and $72 \mathrm{~h}$ were determined in percentages [33].

Consistently with previous studies, also in our analysis no method has been proven superior. Although our research included the largest number of newborn infants investigated so far, we did not observe additional clinical benefit of WBC technique. Despite the lack of clinical advantages, the simplicity of usage of WBC (due to servo-control) should be emphasized. 
The limitation of this study was a lack of randomization and a smaller sample of WBC group.

\section{CONCLUSIONS}

Both methods of therapeutic hypothermia are comparable. We did not find significant differences in short term outcomes and the risk of adverse effects between SHC vs. WBC in newborns with HIE. Our results require confirmation in the follow-up observation. The tendency to higher rate of PPHN in WBC group should be confirmed in subsequent studies

\section{Acknowledgements}

We wish to express our thankfulness for the consent given by all the parents of the patients involved in the study. We would also like to thank all the co-operating regional hospitals.

\section{Funding}

Funding NN407547538 form Polish Ministry of Education and Science.

Clinical Trials.gov. ID NCT02499393.

The authors declare, that this is an original study as well it has not been previously published and has not been submitted for publication elsewhere while under consideration.

\section{REFERENCES}

1. WHO. http://www.childmortality.org/ Global Health Observatory (GHO) (2016).

2. Yager J, Towfighi J, Vannucci RC. Influence of mild hypothermia on hypoxic-ischemic brain damage in the immature rat. Pediatr Res. 1993; 34(4): 525-529, doi: 10.1203/00006450-199310000-00029, indexed in Pubmed: 8255688.

3. Thoresen M. Cooling the asphyxiated brain - ready for clinical trials? Eur J Pediatr. 1999; 158 Suppl 1: S5-S8, indexed in Pubmed: 10592091.

4. Wagner $\mathrm{CL}$, Eicher DJ, Katikaneni LD, et al. The use of hypothermia: a role in the treatment of neonatal asphyxia? Pediatr Neurol. 1999; 21(1): 429-443, indexed in Pubmed: 10428427.

5. Eicher DJ, Wagner $C L$, Katikaneni $L P$, et al. Moderate hypothermia in neonatal encephalopathy: safety outcomes. Pediatr Neurol. 2005; 32(1): 18-24, doi: 10.1016/j.pediatrneurol.2004.06.015, indexed in Pubmed: 15607599.

6. Gunn AJ, Battin M, Gluckman PD, et al. Therapeutic hypothermia: from lab to NICU. J Perinat Med. 2005; 33(4):340-346, doi: 10.1515/JPM.2005.061, indexed in Pubmed: 16207121.

7. Battin MR, Thoresen M, Robinson E, et al. Cool Cap Trial Group. Does head cooling with mild systemic hypothermia affect requirement for blood pressure support? Pediatrics. 2009; 123(3): 1031-1036, doi: 10.1542/peds.2008-1610, indexed in Pubmed: 19255036.

8. Shankaran S, Laptook A, Wright LL, et al. Whole-body hypothermia for neonatal encephalopathy: animal observations as a basis for a randomized, controlled pilot study in term infants. Pediatrics. 2002; 110(2 Pt 1): 377-385, doi: 10.1542/peds.110.2.377, indexed in Pubmed: 12165594.

9. Shankaran S, Natarajan G, Chalak L, et al. Eunice Kennedy Shriver National Institute of Child Health and Human Development Neonatal Research Network, Eunice Kennedy Shriver National Institute of Child Health and Human Development Neonatal Research Network, Eunice Kennedy Shriver National Institute of Child Health and Human Development Neonatal Research Network, NICHD Neonatal Research Network, National Institute of Child Health and Human Development Neonatal Research Network. Whole-body hypothermia for neonates with hypoxic-ischemic encephalopathy. N Engl J Med. 2005; 353(15): 1574-1584, doi: 10.1056/NEJMcps050929, indexed in Pubmed: 16221780.
10. Simbruner G, Mittal RA, Rohlmann F, et al. neo.nEURO.network Trial Participants. Systemic hypothermia after neonatal encephalopathy: outcomes of neo.nEURO.network RCT. Pediatrics. 2010; 126(4): e771-e778, doi: 10.1542/peds.2009-2441, indexed in Pubmed: 20855387.

11. Azzopardi D, Strohm B, Edwards AD, et al. Steering Group and TOBY Cooling Register participants. Treatment of asphyxiated newborns with moderate hypothermia in routine clinical practice: how cooling is managed in the UK outside a clinical trial. Arch Dis Child Fetal Neonatal Ed. 2009; 94(4): F260-F264, doi: 10.1136/adc.2008.146977, indexed in Pubmed: 19060009.

12. Jacobs SE, Morley CJ, Inder TE, et al. Infant Cooling Evaluation Collaboration. Whole-body hypothermia for term and near-term newborns with hypoxic-ischemic encephalopathy: a randomized controlled trial. Arch Pediatr Adolesc Med. 2011; 165(8): 692-700, doi: 10.1001/archpediatrics.2011.43, indexed in Pubmed: 21464374.

13. Thoresen M, Hellström-Westas L, Liu X, et al. Effect of hypothermia on amplitude-integrated electroencephalogram in infants with asphyxia. Pediatrics. 2010; 126(1): e131-e139, doi: 10.1542/peds.2009-2938, indexed in Pubmed: 20566612.

14. Takenouchi T, Iwata $O$, Nabetani $M$, et al. Therapeutic hypothermia for neonatal encephalopathy. Brain Dev. 2012; 34: 165-70.

15. Allen KA. Moderate hypothermia: is selective head cooling or whole body cooling better? Adv Neonatal Care. 2014; 14(2): 113-118, doi: 10.1097/ANC.0000000000000059, indexed in Pubmed: 24675631.

16. Sarnat HB, Sarnat MS. Neonatal encephalopathy following fetal distress. A clinical and electroencephalographic study. Arch Neurol. 1976; 33(10): 696-705, indexed in Pubmed: 987769.

17. Thompson $C M$, Puterman AS, Linley $L L$, et al. The value of a scoring system for hypoxic ischaemic encephalopathy in predicting neurodevelopmental outcome. Acta Paediatr. 1997; 86(7): 757-761, indexed in Pubmed: 9240886.

18. Tooley J, Satas S, Eagle R, et al. Significant selective head cooling can be maintained long-term after global hypoxia ischemia in newborn piglets. Pediatrics. 2002; 109(4): 643-649, doi: 10.1542/peds.109.4.643, indexed in Pubmed: 11927709.

19. Mellergård $P$, Mellergård $P$. Monitoring of rectal, epidural, and intraventricular temperature in neurosurgical patients. Acta Neurochir Suppl (Wien). 1994; 60(1): 485-487, indexed in Pubmed: 7976627.

20. Kiyatkin EA, Sharma HS. Permeability of the blood-brain barrier depends on brain temperature. Neuroscience. 2009; 161(3): 926-939, doi: 10.1016/j.neuroscience.2009.04.004, indexed in Pubmed: 19362131.

21. Perlman JM, Wyllie J, Kattwinkel J, et al. Neonatal resuscitation: 2010 International Consensus on Cardiopulmonary Resuscitation and Emergency Cardiovascular Care Science With Treatment Recommendations. Circulation. 2010; 19(122): 516-538.

22. Gluckman PD, Wyatt JS, Azzopardi D, et al. Selective head cooling with mild systemic hypothermia after neonatal encephalopathy: multicentre randomised trial. Lancet. 2005; 365(9460):663-670, doi: 10.1016/S0140-6736(05)17946-X, indexed in Pubmed: 15721471.

23. Zhou WH. Selective Head Cooling with Mild Systemic Hypothermia after Neonatal Hypoxic-Ischemic Encephalopathy: A Multicenter Randomized Controlled Trial in China. J Pediatr. 2009; 157: 367-72.

24. Azzopardi DV, Strohm B, Edwards AD, et al.TOBY Study Group. Moderate hypothermia to treat perinatal asphyxial encephalopathy. N Engl J Med. 2009; 361(14): 1349-1358, doi: 10.1056/NEJMoa0900854, indexed in Pubmed: 19797281.

25. Sarkar S, Barks JD, Bhagat l, et al. Pulmonary dysfunction and therapeutic hypothermia in asphyxiated newborns: whole body versus selective head cooling. Am J Perinatol. 2009; 26(4): 265-270, doi: 10.1055/s-00281103154, indexed in Pubmed: 19021092.

26. Sarkar S, Barks JD, Bhagat I, et al. Effects of therapeutic hypothermia on multiorgan dysfunction in asphyxiated newborns: whole-body cooling versus selective head cooling. J Perinatol. 2009; 29(8): 558-563, doi: 10.1038/jp.2009.37, indexed in Pubmed: 19322190.

27. Atıcı A, Çelik Y, Gülaşı S, et al. Comparison of selective head cooling therapy and whole body cooling therapy in newborns with hypoxic ischemic encephalopathy: short term results. Turk Pediatri Ars. 2015; 50(1): 27-36, doi: 10.5152/tpa.2015.2167, indexed in Pubmed: 26078694.

28. Hoque N, Chakkarapani E, Liu X, et al. A comparison of cooling methods used in therapeutic hypothermia for perinatal asphyxia. Pediatrics. 2010; 126(1): e124-e130, doi: 10.1542/peds.2009-2995, indexed in Pubmed: 20530071.

29. Jacobs SE, Berg M, Hunt $R$, et al. Cooling for newborns with hypoxic ischaemic encephalopathy. Cochrane Database Syst Rev. 2013(1): 
CD003311, doi: 10.1002/14651858.CD003311.pub3, indexed in Pubmed: 23440789.

30. Boutaybi N, Razenberg F, Smits-Wintjens VE, et al. Neonatal thrombocytopenia after perinatal asphyxia treated with hypothermia: a retrospective case control study. Int J Pediatr. 2014; 2014: 760654, doi: 10.1155/2014/760654, indexed in Pubmed: 25214854.

31. Shah PS, Ohlsson A, Perlman M. Hypothermia to treat neonatal hypoxic ischemic encephalopathy: systematic review. Arch Pediatr Adolesc Med.
2007: 161(10): 951-958, doi: 10.1001/archpedi.161.10.951, indexed in Pubmed: 17909138

32. Celik Y, Atıcı A, Gulası $S$, et al. Comparison of selective head cooling versus whole-body cooling. Pediatr Int. 2016; 58(1): 27-33, doi: 10.1111/ped.12747, indexed in Pubmed: 26189647.

33. Jacobs $S E$, Berg $M$, Hunt $R$, et al. Cooling for newborns with hypoxic ischaemic encephalopathy. Cochrane Database Syst Rev. 2003(4): CD003311, doi: 10.1002/14651858.CD003311, indexed in Pubmed: 14583966. 